\title{
REPRESENTATIVE HEIGHTS FOR ASSESSING WHOLE-TREE VALUES AND THE WITHIN-TREE VARIATIONS OF DERIVED WOOD PROPERTIES IN EUCALYPTUS CAMALDULENSIS AND E. GLOBULUS
}

\author{
Jyunichi Ohshima \\ Graduate Student \\ Shinso Yokota \\ Associate Professor \\ Nobuo Yoshizawa \\ Professor \\ Department of Forest Science \\ Faculty of Agriculture \\ Utsunomiya University \\ 350 Mine-machi \\ Utsunomiya, 321-8505, Japan \\ and \\ Toshihiro Ona \\ Associate Professor \\ Department of Forest and Forest Products Sciences \\ Graduate School of Bioresource and Bioenvironmental Sciences \\ Kyushu University, 6-10-1 \\ Hakozaki, Higashi-ku \\ Fukuoka, 812-8581, Japan
}

(Received October 2003)

\begin{abstract}
The representative heights in the trunk to indicate whole-tree values and the within-tree variations of derived wood properties, namely flexibility coefficient, wall coverage ratio, vessel diameter radial/tangential $(\mathrm{R} / \mathrm{T})$ ratio, fiber diameter R/T ratio, and fiber coarseness, were examined in Eucalyptus camaldulensis and E. globulus trees. In both species, within-tree variations were generally observed as high in the upper and outer parts of the trunk for wall coverage ratio and in the lower parts for flexibility coefficient and vessel diameter R/T ratio. In E. camaldulensis, within-tree variations were observed as high in the upper and outer parts of the trunk for fiber coarseness, and in the lower and inner parts for fiber diameter R/T ratio. In E. globulus, within-tree variations were observed as high in the outer parts for fiber coarseness, but fiber diameter $\mathrm{R} / \mathrm{T}$ ratio had no clear trend. The representative height assessing the derived wood properties was $2.8 \mathrm{~m}$ in E. camaldulensis and $1.8 \mathrm{~m}$ in E. globulus, regardless of differences in tree height (growth rate). No representative height was found for wall coverage ratio.
\end{abstract}

Keywords: Eucalyptus, derived wood properties, within-tree variation, representative height, quality breeding.

\section{INTRODUCTION}

Comprehensive breeding programs have been performed to quantify both species and individuals within a species possessing high pulp yield and pulp quality (Ona and Sonoda 1996). Eucalyptus is one of the species examined since it shows good growth and favorable chemical quality for pulp production such as less content in lignin and extractives (Miranda and Pereira 
2001, 2002; Kibblewhite and McKenzie 1999), and it is an ideal pulp for printing paper for the following reasons (Cornéer 1986).

1. The structure and pore size distribution of paper are comparatively homogeneous.

2. Paper opacity is high.

3. Pulp shows good runnability on a paper machine and a printer drum.

4. Pulp shows high water drainage rate to reduce the cost of drying and to increase capacity.

These are derived from the fact that Eucalyptus pulp fibers are short, narrow, and stiff, and fiber number per gram of pulp is high; therefore, quality breeding is encouraged to obtain uniform and consistent quality of pulp.

In the practical quality breeding program, a nondestructive sampling method using an increment core is desirable for the assessment of pulp properties (Ona et al. 1996). However, with limited sampling, significantly high relationships between wood and pulp properties are required for the estimation of whole-tree properties because it is not easy to make pulp from an increment core with a conventional size of $5-12-\mathrm{mm}$ diameter.

Derived wood properties, such as flexibility coefficient, wall coverage ratio, vessel diameter $\mathrm{R} / \mathrm{T}$ ratio, and fiber coarseness, have been recognized as important traits for pulp and paper properties in Eucalyptus (DuPlooy 1980; Malan et al. 1994; Ona et al. 2001). For example, flexibility coefficient is related to pulp yield and digestibility (Ona et al. 2001). Ona et al. (2001) also reported the importance of vessel $\mathrm{R} / \mathrm{T}$ ratio to breed trees for pulp strength in E. globulus. On the other hand, the heritability of fiber diameter is reported high in Pinus radiata (Kibblewhite 1999; Shelbourne et al. 1997; Nyakuengama et al. 1997) and moderate in Pinus pinaster (Pot et al. 2002). The heritabilities of fiber lumen diameter and of fiber wall thickness, which are factors of flexibility coefficient and wall coverage ratio, are reported both moderate in Picea abies (Hannrup et al. 2004). The heritability of fiber coarseness is reported high in Pinus pinaster (Pot et al. 2002) and low in Eucalyptus regnans (Raymond et al. 1998). Fur- thermore, the heritabilities of percentages in fiber, ray and vessel tissues, and fiber length, which are indirectly related to the derived wood properties (Ona et al. 2001), are reported high in Eucalyptus grandis (Malan 1988). These suggest that derived wood properties could be used as selection indices for quality breeding.

The issue for the increment core method is selection of the core-sampling position that best represents whole-tree values. The examination of within-tree variations of derived wood properties is essential to determine the core-sampling position accurately. Within-tree variations of derived wood properties, such as flexibility coefficient and fiber coarseness in Eucalyptus, have been reported previously, sometimes using pulp fibers (Malan and Gerischer 1987; Varghese et al. 1995; Hudson et al. 1998; Raymond et al. 1998; Hudson et al. 2000; Muneri and Raymond 2001). However, little has been presented on within-tree variations of derived wood properties including vessel diameter $\mathrm{R} / \mathrm{T}$ ratio which significantly correlates to breaking length in $E u$ calyptus (Ona et al. 2001). The most appropriate core-sampling position is reported for fiber coarseness in Eucalyptus using fibers in pulp or in wood (Raymond et al. 1998; Muneri and Raymond 2001; Hudson et al. 2001), but not for flexibility coefficient on a whole-tree basis. Since the representative height for vessel frequency was not obtained (Ohshima et al. 2004), the most suitable derived wood property as a selection index for quality breeding is not yet sufficiently investigated.

In this paper, we examined the within-tree variations and the representative heights in the trunk to indicate whole-tree values of derived wood properties, namely flexibility coefficient, wall coverage ratio, vessel diameter $\mathrm{R} / \mathrm{T}$ ratio, fiber diameter $\mathrm{R} / \mathrm{T}$ ratio, and fiber coarseness in E. camaldulensis and E. globulus trees.

\section{MATERIALS AND METHODS}

\section{Materials}

Two trees each of 14-year-old E. camaldulensis and E. globulus (numbered as 1 and 2 for each species) grown at Department of Conserva- 
tion and Land Management in Western Australia (annual average temperature: $15.5^{\circ} \mathrm{C}$, annual rainfall: $1,000 \mathrm{~mm}$ ) were utilized for this study. The tree No. 1 and No. 2 possessed average and superior growth characteristics, respectively. Estimated whole-tree height and diameter at breast height after debarking for each tree were as follows: E. camaldulensis No. 1: $15.2 \mathrm{~m}, 18.8$ cm; No. 2: $18.1 \mathrm{~m}, 23.5 \mathrm{~cm}$; E. globulus No. 1: 19.9 m, 24.4 cm; No. 2: 30.0 m, $23.8 \mathrm{~cm}$.

After the sample trees were cut down, debarked discs in 6-cm thickness were obtained from $0.3 \mathrm{~m}$ above the ground with $1-\mathrm{m}$ interval up to the height at an $8-\mathrm{cm}$ diameter. Two strips in 2-cm width were removed from the center of each disc. Then the strips were divided into $2 \mathrm{~cm}$ each from the center, and about $2-\mathrm{cm} \times 2-\mathrm{cm} \times$ 6-cm wood blocks were obtained. These blocks were utilized for the determination of derived wood properties.

\section{Determination of derived wood properties}

Cross sections, $15-\mu \mathrm{m}$ thickness, were prepared from respective block samples and stained with safranin to mount in Bioleit (Ohken Shoji, Tokyo, Japan). The measurement of cell morphology of 50 fibers and 30 vessels randomly selected was made with an Olympus $\mathrm{BH}-2$ light microscope (Olympus, Tokyo, Japan) and an image processing software, NIH Image 1.62 (National Institute of Health, Bethesda, MD).

The following derived wood properties were calculated using measured fiber and vessel morphology

- Flexibility coefficient $=$ fiber lumen diameter / fiber diameter (Wangaard 1962)

- Wall coverage ratio $=$ double fiber wall thickness / fiber diameter (Mottet 1965)

- Vessel diameter $\mathrm{R} / \mathrm{T}$ ratio = radial vessel diameter / tangential vessel diameter (Ona et al. 2001)

- Fiber diameter $\mathrm{R} / \mathrm{T}$ ratio = radial fiber diameter / tangential fiber diameter (Ona et al. 2001)

- Fiber coarseness $=$ fiber wall area $\times$ fiber wall density (assuming density of $1.5 \times 10^{6}$ $\mathrm{g} / \mathrm{m}^{3}$ ) (Hudson et al. 2000)

\section{Whole-tree and-disc values of derived wood properties}

Since uneven growth was recognized for some directions and selected heights in the trunk, the whole-tree values and whole-disc values of derived wood properties were determined according to Ona et al. (1995) as follows (Fig. 1). The unmeasured parts (A) between two axially adjacent measured parts (a and b) were calculated as the average of the measured parts (a and b). For other unmeasured parts (B and C or $\mathrm{E}$ ), the same values radially adjacent to the measured parts ( $b$ and $c$ ) or the unmeasured part (D) were utilized. The unmeasured part D was calculated as the average of axially adjacent measured part (c) and calculated part (B). Each measured or calculated part was considered to own the same quality as its concentric circled section. Based on these, whole-tree values and whole-disc values at given heights were determined as weighted values by wood volume. The student $t$ test was performed by SPSS 11.0.1J (SPSS, Chicago, IL, USA).

\section{RESULTS AND DISCUSSION}

\section{Within-tree variation of flexibility coefficient}

The derived wood properties are summarized in Table 1 . Within-tree variation of flexibility coefficient in E. camaldulensis and E. globulus are shown in Figs. 1 and 2, respectively.

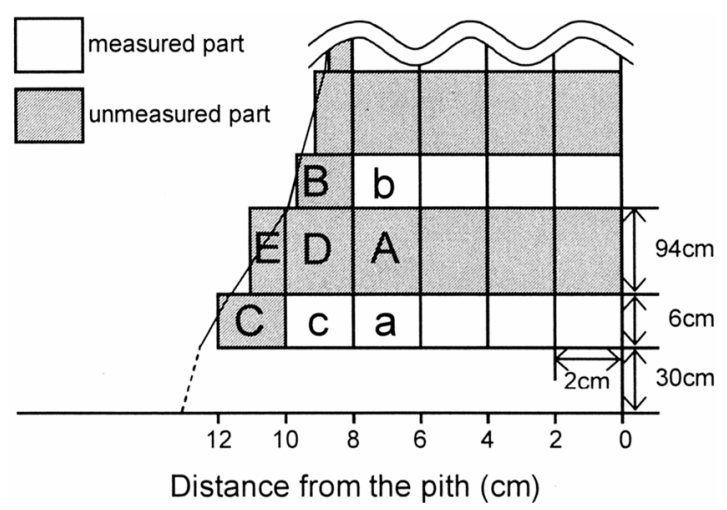

FIG. 1. Derived wood property estimation for unmeasured parts. 
TABLE 1. Derived wood properties (average \pm standard deviation).

\begin{tabular}{lccccc}
\hline & \multicolumn{2}{c}{ E. camaldulensis } & & \multicolumn{2}{c}{ E. globulus } \\
\cline { 2 - 3 } \cline { 5 - 6 } Traits & $\begin{array}{c}\text { No. } 1 \\
(\mathrm{n}=33)\end{array}$ & $\begin{array}{c}\text { No. } 2 \\
(\mathrm{n}=44)\end{array}$ & & $\begin{array}{c}\text { No. } 1 \\
(\mathrm{n}=56)\end{array}$ & $\begin{array}{c}\text { No. } 2 \\
(\mathrm{n}=93)\end{array}$ \\
\hline Flexbility coefficient & $0.68 \pm 0.05$ & $0.68 \pm 0.04$ & & $0.66 \pm 0.04$ & $0.62 \pm 0.08$ \\
Wall coverage ratio & $0.32 \pm 0.05$ & $0.32 \pm 0.04$ & & $0.34 \pm 0.04$ & $0.38 \pm 0.08$ \\
Vessel diameter R/T ratio & $1.35 \pm 0.04$ & $1.45 \pm 0.10$ & & $1.47 \pm 0.08$ & $1.39 \pm 0.09$ \\
Fiber diameter R/T ratio & $1.23 \pm 0.09$ & $1.17 \pm 0.09$ & & $1.28 \pm 0.06$ & $1.21 \pm 0.09$ \\
Fiber coarseness (mg/m) & $0.088 \pm 0.009$ & $0.091 \pm 0.010$ & & $0.129 \pm 0.025$ & $0.135 \pm 0.036$ \\
\hline
\end{tabular}

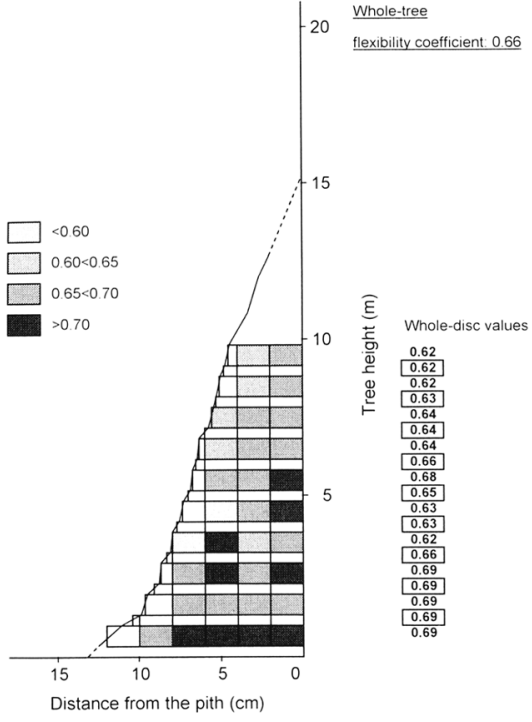

E. camaldulensis No. 1

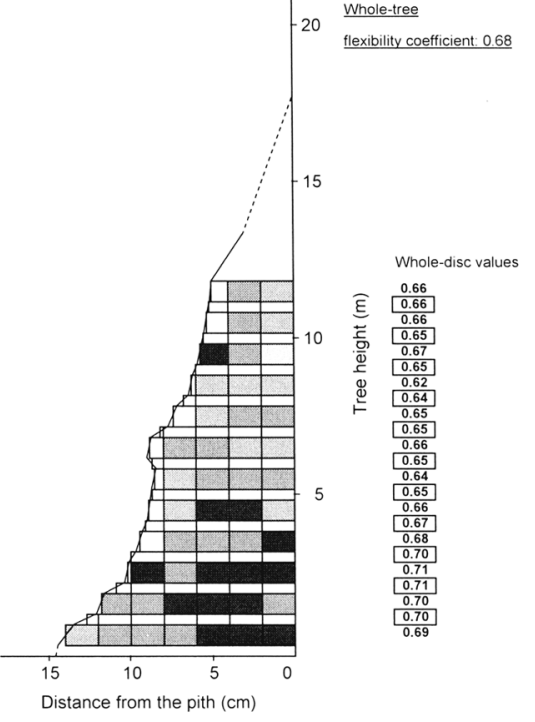

E. camaldulensis No. 2

FIG. 2. Within-tree variation of flexibility coefficient in E. camaldulensis. Note: unboxed and boxed digits represent weighted whole-disc values calculated from actual measurements and by estimation.

In both E. camaldulensis and E. globulus, the trees had high flexibility coefficient in the lower parts of the trunk. In the radial direction, a trend of decreasing flexibility coefficient was observed from pith to bark for E. camaldulensis, except the upper parts of No. 2, and the lower parts of E. globulus No. 2. However, no clear trend was observed for E. globulus, except the lower parts of No. 2. In the axial direction, a trend of decreasing flexibility coefficient was observed from bottom to top for both species.

The trend of decreasing flexibility coefficient from pith to bark in the radial direction was reported for E. grandis (Malan and Gerischer
1987; Varghese et al. 1995). Our results are in good agreement with these reports for both species. On the other hand, the trend of flexibility coefficient, similar to fiber lumen diameter previously obtained (Ohshima et al. 2003) was observed in both species. This might be caused by the larger percentage in variation of fiber lumen diameter to fiber diameter.

Ona et al. (2001) reported that flexibility coefficient was significantly related to pulp yield (negatively) and to digestibility (positively) in $E$. camaldulensis. The results obtained suggest the lower parts of the trunk will have lower pulp yield and digestibility than other parts. 


\section{Within-tree variation of wall coverage ratio}

Within-tree variations of wall coverage ratio in E. camaldulensis and E. globulus are shown in Figs. 3 and 4, respectively. In both species, the trees had high wall coverage ratio in the upper and outer parts of the trunk. In the radial direction, a weak trend of increasing wall coverage ratio was observed from pith to bark for E. camaldulensis, except the upper parts of No. 2, and the lower parts of E. globulus No. 2. However, no clear trend was observed for E. globulus, except the lower parts of No. 2. In the axial direction, a trend of increasing wall coverage ratio was observed from bottom to top for both species, except the outer parts of E. globulus No. 2.

Malan and Gerischer (1987) reported that wall coverage ratio in E. grandis increased from the pith to the bark in the radial direction. This agrees with our results obtained for both species. The wall coverage ratio showed the opposite trend to flexibility coefficient because wall coverage ratio is 1 minus flexibility coefficient, given the ratio of lumen diameter divided by external fiber diameter. Within-tree variation of wall coverage ratio is similar to that of fiber wall thickness and is thought to be dependent on it (Ohshima et al. 2003).

\section{Within-tree variation of vessel diameter $R / T$ ratio}

Within-tree variation of vessel diameter $\mathrm{R} / \mathrm{T}$ ratio in E. camaldulensis and E. globulus is shown in Figs. 5 and 6, respectively. Both $E$. camaldulensis and E. globulus had high vessel diameter $\mathrm{R} / \mathrm{T}$ ratio in the lower parts of the trunk, although the lower parts of E. camaldulensis No.

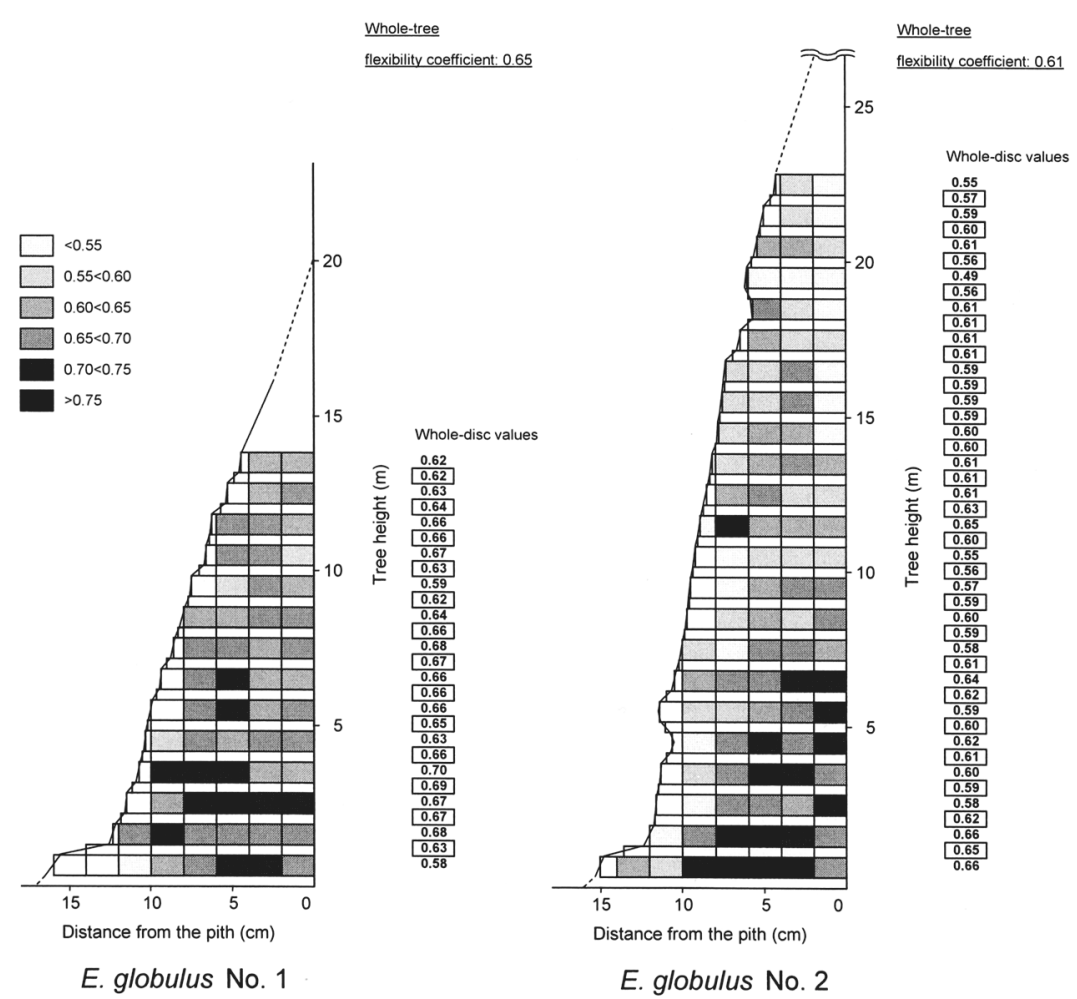

FIG. 3. Within-tree variation of flexibility coefficient in E. globulus. See note in Fig. 1. 


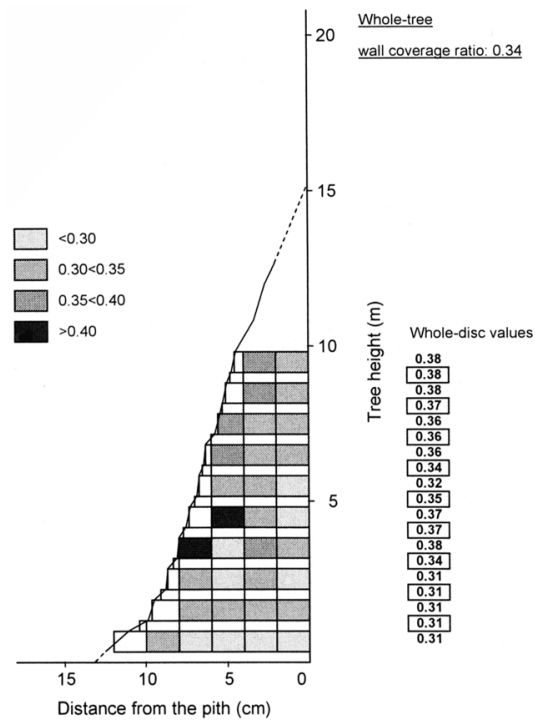

E. camaldulensis No. 1

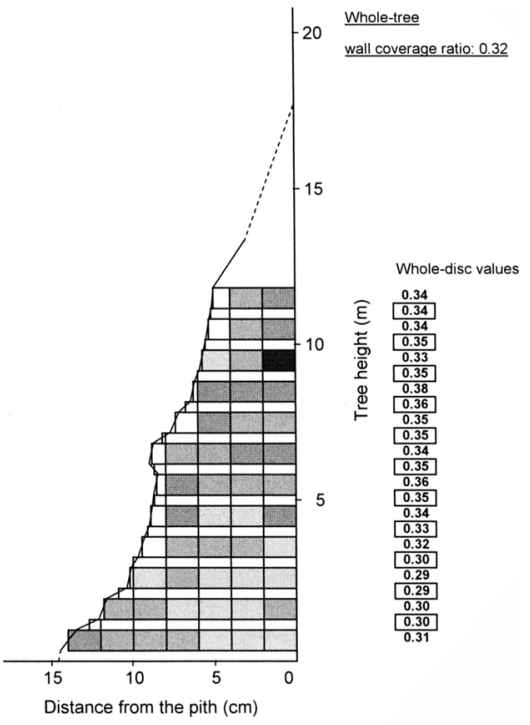

E. camaldulensis No. 2

FIG. 4. Within-tree variation of wall coverage ratio in E. camaldulensis. See note in Fig. 1.

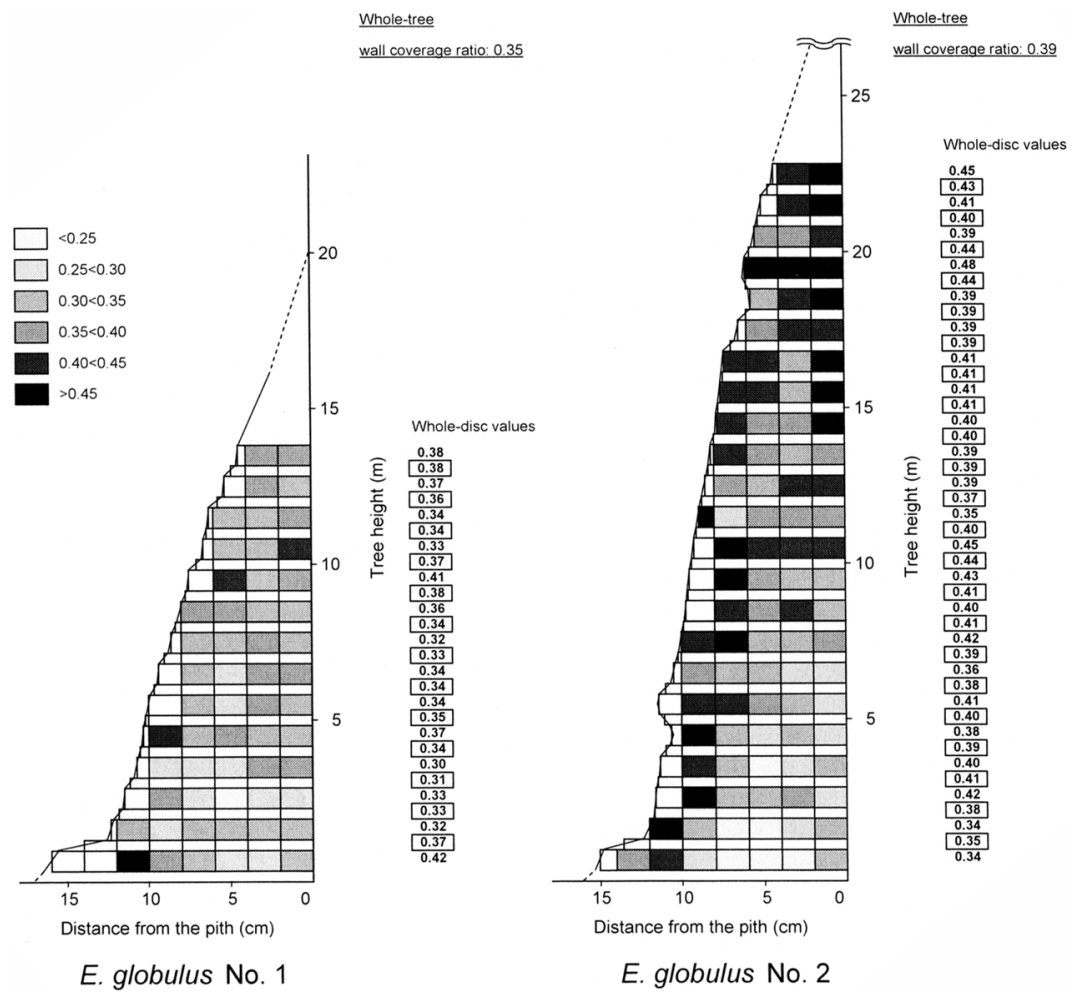

FIG. 5. Within-tree variation of vessel diamter R/T ratio in E. camaldulensis. See note in Fig. 1. 


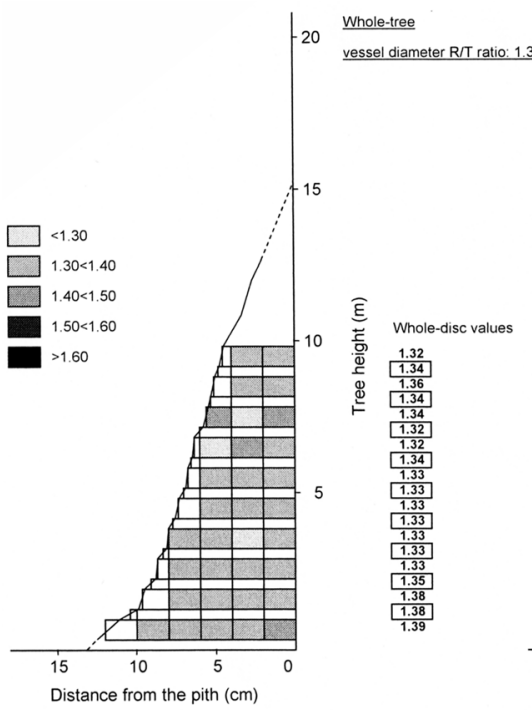

E. camaldulensis No. 1

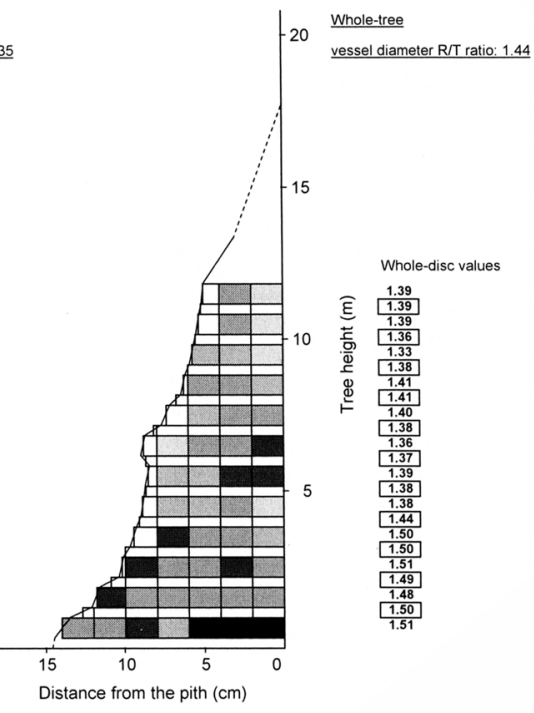

E. camaldulensis No. 2

FIG. 6. Within-tree variation of vessel diameter R/T ratio in E. camaldulensis. See note in Fig. 1.

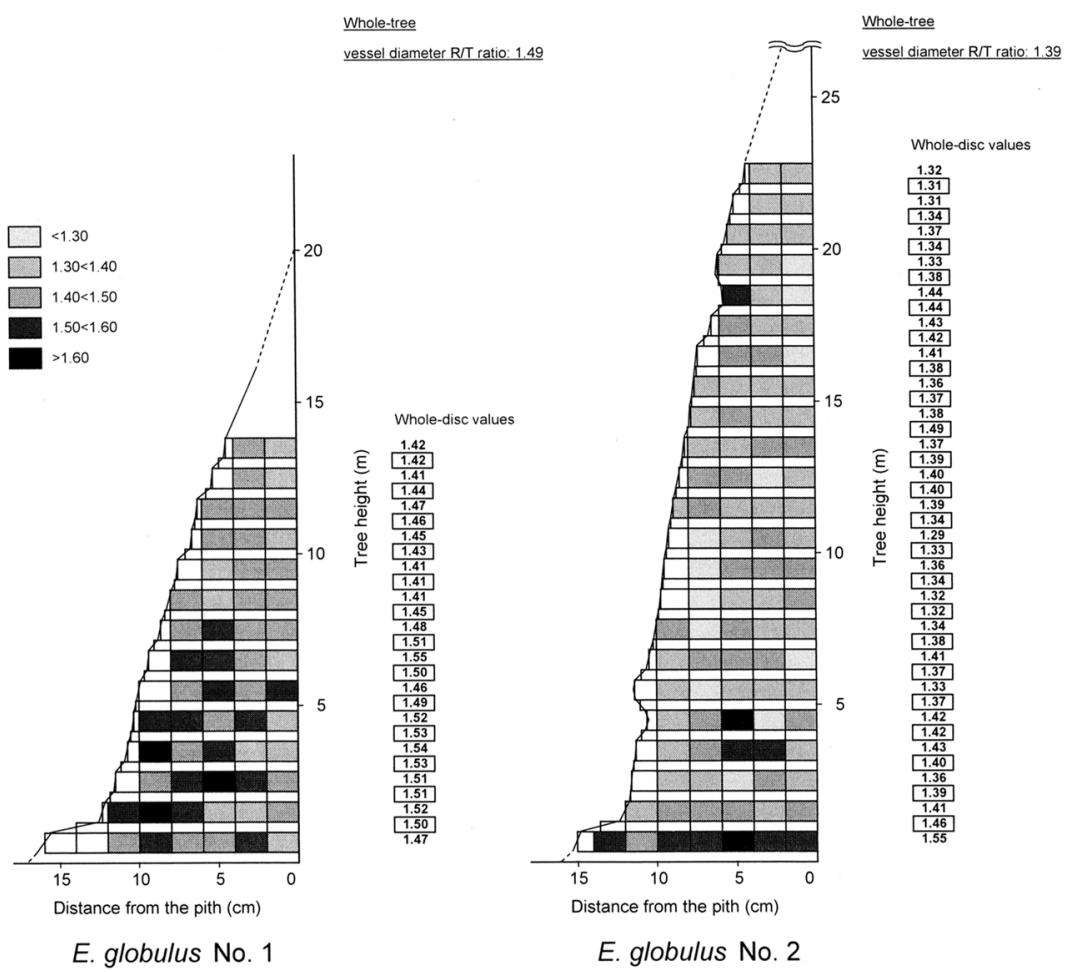

FIG. 7. Within-tree variation of vessel diameter R/T ratio in E. globulus. See note in Fig. 1. 
2 showed higher vessel diameter $\mathrm{R} / \mathrm{T}$ ratio than No. 1. Relatively uniform value of vessel diameter $\mathrm{R} / \mathrm{T}$ ratio was observed in the trunk for both species although tree-to-tree variation was large.

Wilson et al. (1997) reported that vessel diameter $\mathrm{R} / \mathrm{T}$ ratio was relatively constant from pith to bark in the radial direction, similar to our results. On the other hand, the trend of within-tree variation of radial diameter in both species was very similar to that of tangential diameter in a previous report (Ohshima et al. 2004). These suggested that the degree of cell enlargement of vessels in both radial and tangential diameters was almost consistent through the trunk.

Significantly positive relationships between vessel diameter $\mathrm{R} / \mathrm{T}$ ratio and pulp strength were reported in E. globulus (Ona et al. 2001) and thus it is considered that the upper and lower parts of the E. globulus trunk will have higher pulp strength than other parts.

\section{Within-tree variation of fiber diameter $R / T$ ratio}

Within-tree variations of fiber diameter $\mathrm{R} / \mathrm{T}$ ratio in E. camaldulensis and E. globulus are shown in Figs. 8 and 9, respectively. In $E$. camaldulensis, both No. 1 and No. 2 trees had high fiber diameter $\mathrm{R} / \mathrm{T}$ ratio in the lower and inner parts of the trunk. In particular, the inner parts in No. 1 showed high values compared to the other parts. There was a weak trend of decreasing fiber diameter $\mathrm{R} / \mathrm{T}$ ratio from pith to bark in the radial direction, and from bottom to top in the axial direction, except the upper parts of No. 1. Tree-to-tree variation was small. In contrast, the E. globulus trees had no clear trend of fiber diameter $\mathrm{R} / \mathrm{T}$ ratio in the trunk. A significantly different trend of fiber diameter $\mathrm{R} / \mathrm{T}$ ratio was observed between species.

The varying trend between species was observed possibly because of the different withintree variations between radial and tangential diameters as reported previously (Ohshima et al. 2003). In E. camaldulensis, high radial diameter and low tangential diameter in the lower and inner parts result in high values of fiber diameter $\mathrm{R} / \mathrm{T}$ ratio, and low radial diameter and high tangential diameter in the outer parts result in low values of fiber diameter $\mathrm{R} / \mathrm{T}$ ratio. On the other hand, a similar trend between radial and tangen-

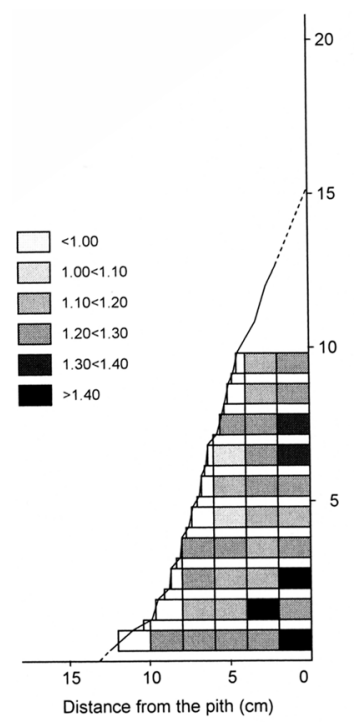

E. camaldulensis No. 1

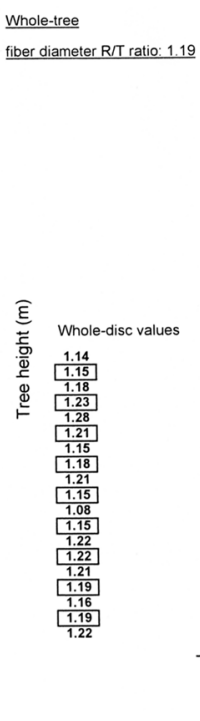

(n)

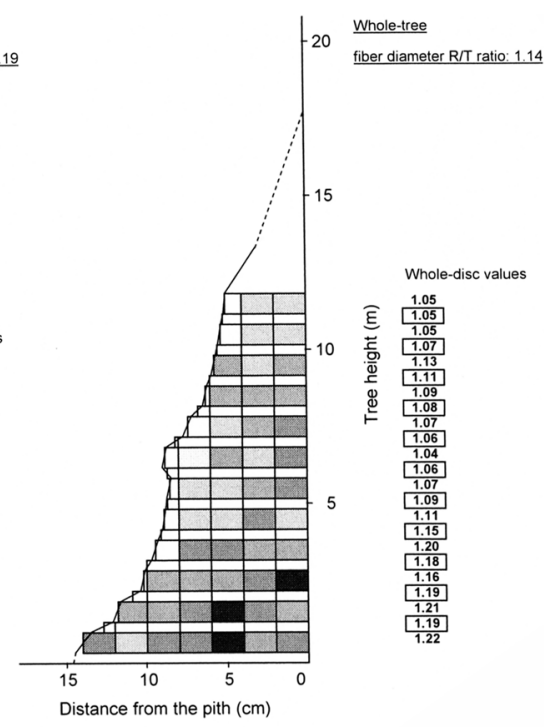

E. camaldulensis No. 2

FIG. 8. Within-tree variation of fiber diameter R/T ratio in E. camaldulensis. See note in Fig. 1. 


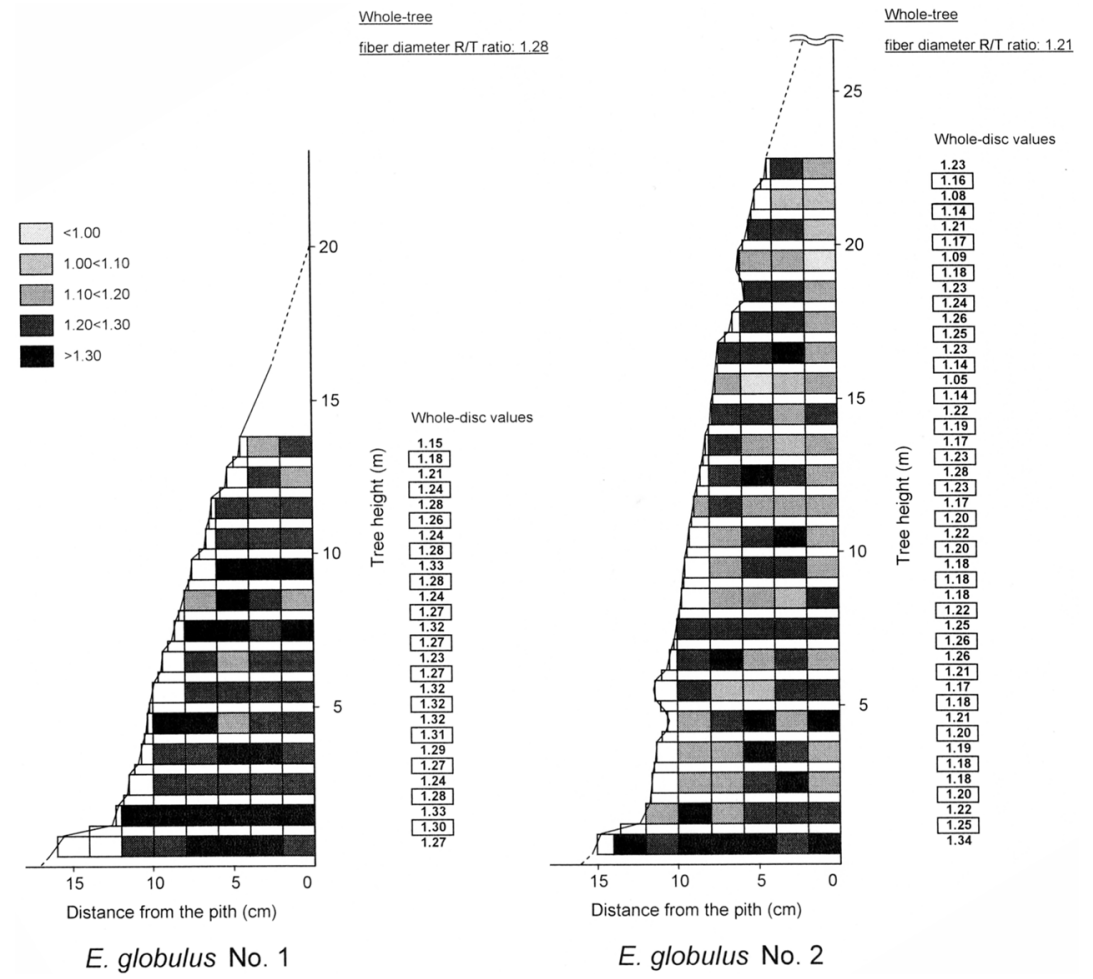

FIG. 9. Within-tree variation of fiber diameter R/T ratio in E. globulus. See note in Fig. 1.

tial diameters in the trunk was observed in $E$. globulus (Ohshima et al. 2003), although the trend was weak compared to vessel diameter. These results suggests an unclear trend of within-tree variation of fiber diameter $\mathrm{R} / \mathrm{T}$ ratio.

\section{Within-tree variation of fiber coarseness}

Within-tree variations of fiber coarseness in $E$. camaldulensis and E. globulus are shown in Figs. 9 and 10, respectively. Both E. camaldulensis trees had high fiber coarseness in the upper and outer parts of the trunk. A trend of increasing fiber coarseness was observed from pith to bark in the radial direction, except the upper parts of tree No. 2. However, no clear trend was observed in the axial direction. Compared to this, the E. globulus trees had high fiber coarseness in the outer parts of the trunk only. In particular, the outer parts of tree No. 2 showed high values compared to the other parts of the trunk. A trend of increasing fiber coarseness was observed from pith to bark in the radial direction, but a relatively uniform trend of increasing fiber coarseness from bottom to top in the axial direction was observed. Consequently, significant between-species differences were observed in fiber coarseness.

In the radial direction, the trend of increasing fiber coarseness from pith to bark was reported in E. globulus (Hudson et al. 2000). We observed similar trends of increasing fiber coarseness in this study, which was not affected by the growth rate difference. In the axial direction, the trend of decreasing pulp fiber coarseness from bottom to top was reported in E. regnans (Raymond et al. 1998), E. globulus, and E. nitens (Muneri and Raymond 2001), and fiber coarseness in wood from $20 \%$ height to 50 or $60 \%$ height in E. globulus (Hudson et al. 2000). Our results obtained for both species are significantly different from these reports. The wood anatomy in the axial direction appears to be less consistent than that in the radial direction (Barrichelo et al. 1983). Sim- 


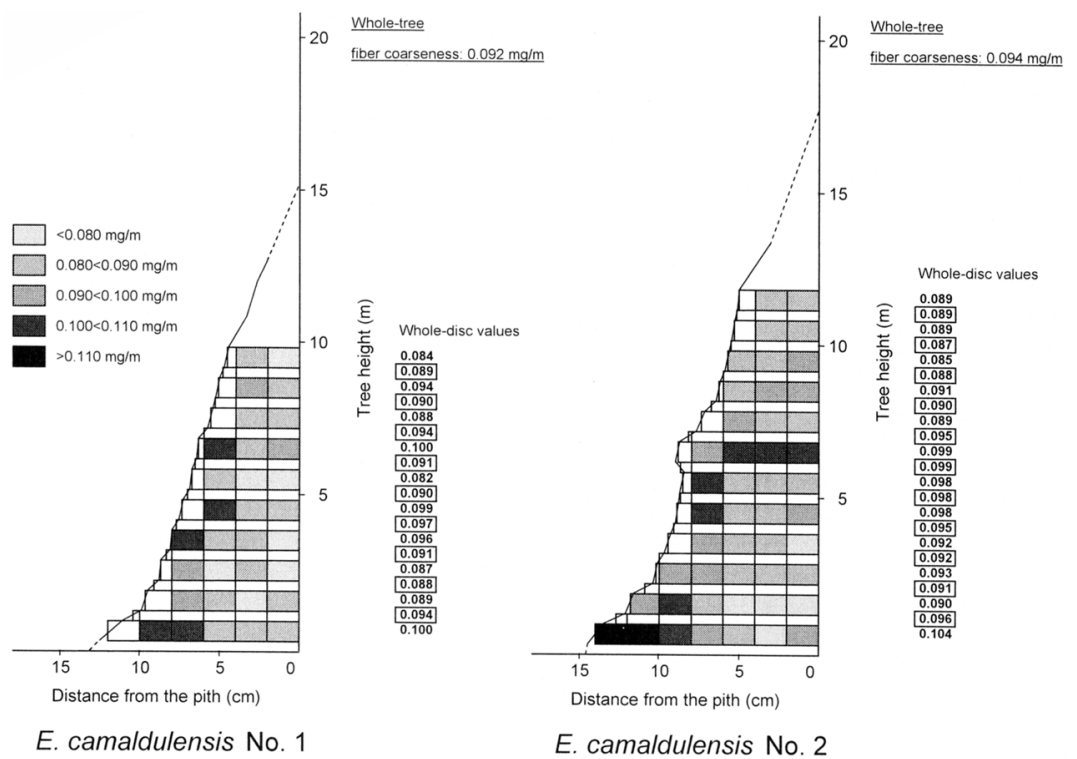

FIG. 10. Within-tree variation of fiber coarseness in E. camaldulensis. See note in Fig. 1.

ilarly, no clear trend or consistent trend was observed in the radial direction of both species.

On the other hand, Muneri and Raymond (2001) reported that pulp fiber coarseness should reflect cell-wall thickness if fiber diameter is considered to be constant. This agrees with our results obtained for fibers in wood for E. camaldulensis because fiber diameter variation is rather small, and within-tree variation of fiber coarseness is very similar to that of wall thickness (Ohshima et al. 2003). Consequently, fiber coarseness in E. camaldulensis is thought to reflect fiber wall thickness. In contrast to this, fiber coarseness in E. globulus does not depend on fiber wall thickness but depends on fiber diameter because within-tree variation of fiber coarseness is very similar to that observed for fiber diameter (Ohshima et al. 2003). This may be caused by the larger variation of fiber diameter compared to fiber wall thickness in E. globulus as reported previously (Ohshima et al. 2003).

Fibers with a higher fiber coarseness character will form bulkier, more porous, and rougher sheets (Clark 1962; Kibblewhite et al. 1991). Our results suggest that E. camaldulensis will have su- perior paper comformability to E. globulus because of lower fiber coarseness (whole-tree fiber coarseness: 0.092, $0.094 \mathrm{mg} / \mathrm{m}$ in E. camaldulensis; $0.145,0.154 \mathrm{mg} / \mathrm{m}$ in E. globulus).

\section{The most appropriate height for sampling an increment core}

The representative heights to express the whole-tree values of derived wood properties were examined below $3.3 \mathrm{~m}$ above the ground, which are suitable to sample an increment core using a stepladder. The representative heights are defined as whole-tree value $\pm 99 \%$ confidence limits by student $t$ test using the combined data of measured parts in two individuals of the corresponding species. The whole-disc values of derived wood properties at given heights in $E$. camaldulensis and E. globulus are summarized in Tables 2 and 3, respectively.

Common representative heights between trees are as follows: in E. camaldulensis, flexibility coefficient: $2.8 \mathrm{~m}$, wall coverage ratio: $2.8 \mathrm{~m}$, vessel diameter $\mathrm{R} / \mathrm{T}$ ratio: none, fiber diameter $\mathrm{R} / \mathrm{T}$ ratio: $2.3,2.8 \mathrm{~m}$, fiber coarseness: $0.8-3.3$ 


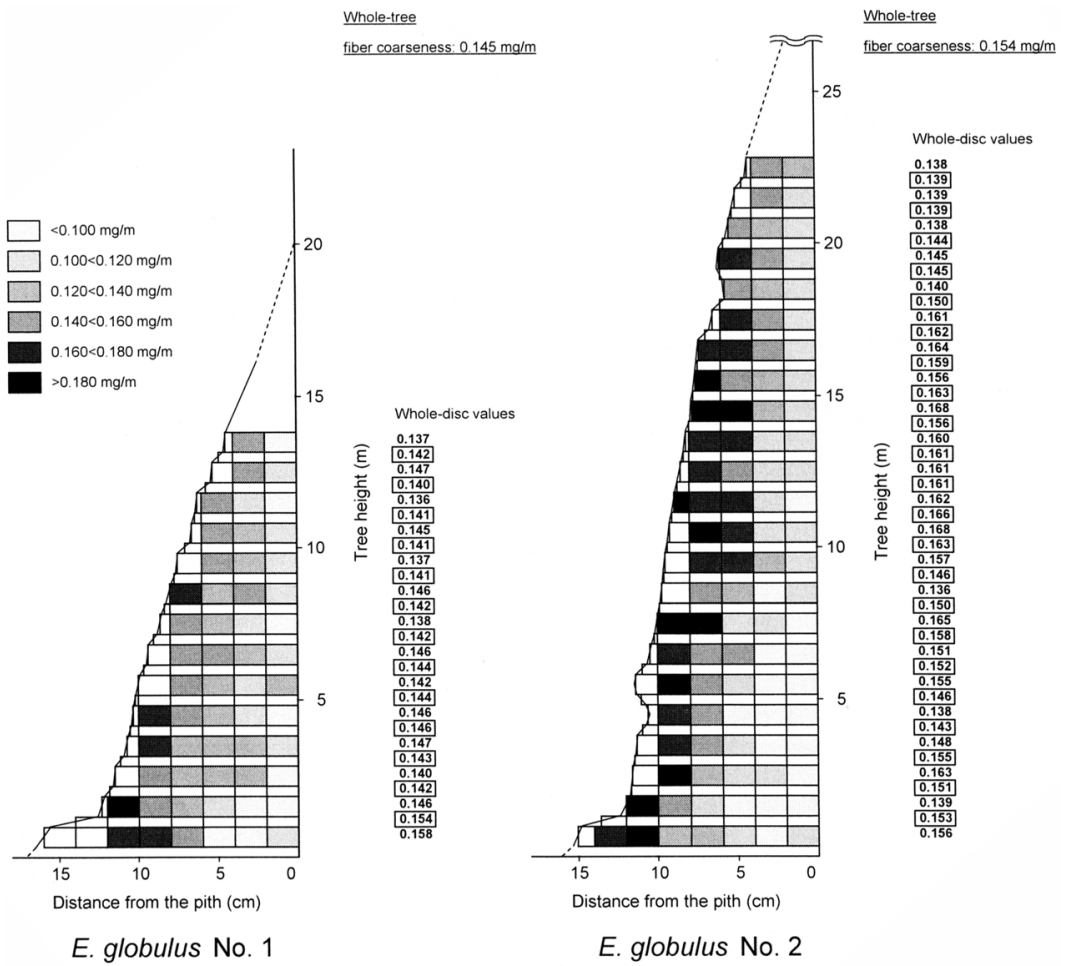

FIG. 11. Within-tree variation of fiber coarseness in E. globulus. See note in Fig. 1.

$\mathrm{m}$; in E. globulus, flexibility coefficient: $1.8 \mathrm{~m}$, wall coverage ratio: $1.8 \mathrm{~m}$, vessel diameter $\mathrm{R} / \mathrm{T}$ ratio: $1.3,1.8 \mathrm{~m}$, fiber diameter $\mathrm{R} / \mathrm{T}$ ratio: 1.8 , $3.3 \mathrm{~m}$, fiber coarseness: 1.8, 2.8, $3.3 \mathrm{~m}$. Consequently, the most appropriate height to sample an increment core is $2.8 \mathrm{~m}$ above the ground for E. camaldulensis (except vessel diameter $\mathrm{R} / \mathrm{T}$ ratio), and $1.8 \mathrm{~m}$ for $E$. globulus. The representative heights were not reflected by the differences in tree height (growth rate) or the within-tree variations of derived wood properties.

The representative height for pulp fiber coarseness is reported as a breast height in $E$. regnans (Raymond et al. 1998). However, Muneri and Raymond (2001) identified $1.5 \mathrm{~m}$ as the optimal sampling height for pulp fiber coarseness in E. globulus and E. nitens. Hudson et al. (2001) reported that the representative height against percentage of tree height was $10 \%$ $(1.5 \mathrm{~m})$ in E. globulus for fiber coarseness in wood, and $5 \%(0.7 \mathrm{~m})$ and $10 \%(1.38 \mathrm{~m})$ in $E$. nitens in the same way. The results obtained in E. camaldulensis were different from these reports, but that of E. globulus was similar to the representative height for fiber coarseness reported by Muneri and Raymond (2001) and Hudson et al. (2001). Previous results obtained for the same sample trees showed the representative height for fiber and vessel morphology was $2.8 \mathrm{~m}$ above the ground for E. camaldulensis, and $1.8 \mathrm{~m}$ for E. globulus (Ohshima et al. 2003, 2004). Together with the results presented here, the representative heights of $2.8 \mathrm{~m}$ for E. camaldulensis and $1.8 \mathrm{~m}$ for E. globulus will be the most appropriate increment core sampling position for fiber and vessel morphology and derived wood properties. However, it should be noted that the height may be less reliable for vessel diameter R/T ratio in E. camaldulensis. Further studies for other wood properties are expected.

These results suggest that it is feasible to estimate whole-tree values of fiber and vessel mor- 
TABLE 2. Whole-tree and -disc values of derived wood properties at given heights with whole-tree values in $\mathrm{E}$. camaldulensis.

\begin{tabular}{|c|c|c|c|}
\hline & & \multicolumn{2}{|c|}{ Whole-disc value } \\
\hline Traits & Height above ground $(\mathrm{m})$ & No. 1 & No. 2 \\
\hline \multirow{7}{*}{ Flexbility coefficient $(-)$} & 3.3 & 0.62 & 0.68 \\
\hline & 2.8 & 0.66 & 0.70 \\
\hline & 2.3 & 0.69 & 0.71 \\
\hline & 1.8 & 0.69 & 0.71 \\
\hline & 1.3 & 0.69 & 0.70 \\
\hline & 0.8 & 0.69 & 0.70 \\
\hline & 0.3 & 0.69 & 0.69 \\
\hline \multicolumn{2}{|c|}{ Whole-tree value $\pm 99 \%$ confidence limits } & $0.66 \pm 0.02$ & $0.68 \pm 0.02$ \\
\hline \multirow[t]{7}{*}{ Wall coverage ratio (-) } & 3.3 & 0.38 & 0.32 \\
\hline & 2.8 & 0.34 & 0.30 \\
\hline & 2.3 & 0.31 & 0.29 \\
\hline & 1.8 & 0.31 & 0.29 \\
\hline & 1.3 & 0.31 & 0.30 \\
\hline & 0.8 & 0.31 & 0.30 \\
\hline & 0.3 & 0.31 & 0.31 \\
\hline \multicolumn{2}{|c|}{ Whole-tree value $\pm 99 \%$ confidence limits } & $0.34 \pm 0.02$ & $0.32 \pm 0.02$ \\
\hline \multirow[t]{7}{*}{ Vessel diameter $\mathrm{R} / \mathrm{T}$ ratio $(-)$} & 3.3 & 1.33 & 1.50 \\
\hline & 2.8 & 1.33 & 1.50 \\
\hline & 2.3 & 1.35 & 1.51 \\
\hline & 1.8 & 1.35 & 1.49 \\
\hline & 1.3 & 1.38 & 148 \\
\hline & 0.8 & $\mathrm{I}, 38$ & 1.50 \\
\hline & 0.3 & 1.39 & 1.51 \\
\hline \multicolumn{2}{|c|}{ Whole-tree value $\pm 99 \%$ confidence limits } & $1.35 \pm 0.02$ & $1.44 \pm 0.04$ \\
\hline \multirow{7}{*}{ Fiber diameter R/T ratio $(-)$} & 3.3 & 1.22 & 1.20 \\
\hline & 2.8 & 1.22 & 1.18 \\
\hline & 2.3 & 1.21 & 1.16 \\
\hline & 1.8 & 1.19 & 1.19 \\
\hline & 1.3 & 1.16 & 1.21 \\
\hline & 0.8 & 1.19 & 1.19 \\
\hline & 0.3 & 1.22 & 1.22 \\
\hline \multicolumn{2}{|c|}{ Whole-tree value $\pm 99 \%$ confidence limits } & $1.19 \pm 0.05$ & $1.14 \pm 0.04$ \\
\hline \multirow[t]{7}{*}{ Fiber coarseness $(\mathrm{mg} / \mathrm{m})$} & 3.3 & 0.096 & 0.092 \\
\hline & 2.8 & 0.091 & 0.092 \\
\hline & 2.3 & 0.087 & 0.093 \\
\hline & 1.8 & 0.088 & 0.091 \\
\hline & 1.3 & 0.089 & 0.090 \\
\hline & 0.8 & 0.094 & 0.096 \\
\hline & 0.3 & 0.100 & 0.104 \\
\hline Whol & value $\pm 99 \%$ confidence limits & $0.092 \pm 0.06$ & $0.094 \pm 0.04$ \\
\hline
\end{tabular}


TABLE 3. Whole-tree and-disc values of derived wood properties at given heights with whole-tree values in E. globulus.

\begin{tabular}{|c|c|c|c|}
\hline & & \multicolumn{2}{|c|}{ Whole-disc value } \\
\hline Traits & Height above ground $(\mathrm{m})$ & No. 1 & No. 2 \\
\hline \multirow{7}{*}{ Flexbility coefficient $(-)$} & 3.3 & 0.70 & 0.60 \\
\hline & 2.8 & 0.69 & 0.59 \\
\hline & 2.3 & 0.67 & 0.56 \\
\hline & 1.8 & 0.67 & 0.62 \\
\hline & 1.3 & 0.68 & 0.66 \\
\hline & 0.8 & 0.63 & 0.65 \\
\hline & 0.3 & 0.58 & 0.66 \\
\hline \multicolumn{2}{|c|}{ Whole-tree value $\pm 99 \%$ confidence limits } & $0.65 \pm 0.02$ & $0.81 \pm 0.02$ \\
\hline \multirow[t]{7}{*}{ Wall coverage ratio $(-)$} & 3.3 & 0.30 & 0.40 \\
\hline & 2.8 & 0.31 & 0.41 \\
\hline & 2.3 & 0.33 & 0.42 \\
\hline & 1.8 & 0.33 & 0.38 \\
\hline & 1.3 & 0.32 & 0.34 \\
\hline & 0.8 & 0.37 & 0.35 \\
\hline & 0.3 & 0.42 & 0.34 \\
\hline \multicolumn{2}{|c|}{ Whole-tree value $\pm 99 \%$ confidence limits } & $0.35 \pm 0.02$ & $0.39 \pm 0.02$ \\
\hline \multirow[t]{7}{*}{ Vessel diameter $\mathrm{R} / \mathrm{T}$ ratio } & 3.3 & 1.54 & 1.43 \\
\hline & 2.8 & 1.53 & 1.40 \\
\hline & 2.3 & 1.51 & 1.36 \\
\hline & 1.8 & 1.51 & 1.39 \\
\hline & 1.3 & 1.52 & 1.41 \\
\hline & 0.8 & 1.50 & 1.46 \\
\hline & 0.3 & 1.47 & 1.55 \\
\hline \multicolumn{2}{|c|}{ Whole-tree value $\pm 99 \%$ confidence limits } & $1.49 \pm 0.03$ & $1.39 \pm 0.02$ \\
\hline \multirow[t]{7}{*}{ Fiber diameter $\mathrm{R} / \mathrm{T}$ ratio $(-$} & 3.3 & 1.29 & 1.19 \\
\hline & 2.8 & 1.27 & 1.18 \\
\hline & 2.3 & 1.24 & 1.18 \\
\hline & 1.8 & 1.28 & 1.20 \\
\hline & 1.3 & 1.33 & 1.22 \\
\hline & 0.8 & 1.30 & 1.25 \\
\hline & 0.3 & 1.27 & 1.34 \\
\hline \multicolumn{2}{|c|}{ Whole-tree value $\pm 99 \%$ confidence limits } & $1.28 \pm 0.02$ & $1.21 \pm 0.02$ \\
\hline \multirow[t]{8}{*}{ Fiber coarseness $(\mathrm{mg} / \mathrm{m})$} & 3.3 & 0.147 & 0.148 \\
\hline & 2.8 & 0.143 & 0.155 \\
\hline & 2.3 & 0.140 & 0.163 \\
\hline & 1.8 & 0.142 & 0.151 \\
\hline & 1.3 & 0.146 & 0.139 \\
\hline & 0.8 & 0.154 & 0.153 \\
\hline & 0.3 & 0.158 & 0.156 \\
\hline & value $\pm 99 \%$ confidence limits & $0.145 \pm 0.06$ & $0.154 \pm 0.07$ \\
\hline
\end{tabular}


phology and derived wood properties using a single increment core sampled at the most appropriate height. These measurements could be used in Eucalyptus tree breeding to improve the pulpwood quality.

\section{ACKNOWLEDGMENTS}

The authors wish to thank Conservation and Land Management (Western Australia) for the sample provision. This research has been partly supported by CREST of JST (Japan Science and Technology) and Oji Paper (Japan).

\section{REFERENCES}

Barrichelo, L. E., J. O. Brito, And A. J. Migliorini. 1983. Estudo da variação longitudinal da densidade básicá de Eucalyptus spp. Silvicultura 28:726-731.

Clark, JD'ARCY. 1962. Effect of fibre coarseness and length. 1. Bulk, burst, tear, fold and tensile tests. Tappi J. 45:628-634.

CORNÉER, B. E. 1986. Eucalyptus-an ideal pulp for printing paper. Pap. Technol. Ind. 26:21-22.

DuPlooy, A. B. J. 1980. The relationship between wood and pulp properties of $E$. grandis (Hill ex-Maide) grown in South Africa. Appita 33:257-264.

Hannrup, B., C. Cahalan, G. Chantre, M. Grabner, B. Karlson, I. L. Bayon, G. L. Jones, U. Müller, H. Pereira, J. C. Rodrigues, S. Rosner, P. Rozenberg, L. Wilhelmsson, AND R. Wimmer. 2004. Genetic parameters of growth and wood quality traits in Picea abies. Scand. J. For. Res. 19:14-29.

Hudson, I., L. Wilson, and K. Van Beveren. 1998. Vessel and fibre property in Eucalyptus globulus and Eucalyptus nitens: Some preliminary results. IAWA J. 19:111-130.

— $\longrightarrow$, AND $\longrightarrow$ 2000. Association of fibre morphology with cambial age and attained height: New oblique axes whole tree variation in Eucalyptus globulus. Appita J. 53:122-140.

$\longrightarrow$, $\longrightarrow$ AND 2001. Between species differences in whole tree maps of fibre properties in $E$. nitens and E. globulus-Utility of control deviation charts to assess optimal sampling height. Appita J. 54:182-189.

Kibblewhite, R. P. 1999. Designer fibres for improved papers through exploiting genetic variation in wood microstructure. Appita J. 52:429-435, 440.

— AND C. J. McKenzIE. 1999. Kraft fibre property variation among 29 trees of 15 year old Eucalyptus fastigata and comparison with E. nitens. Appita J. $52: 218-225$.

- A. D. Bawden, and M. C. Hughes. 1991. Hardwood market kraft fiber and pulp qualities. Appita J. 44:325-332.
Malan, F. S. 1988. Genetic variation in some growth and wood properties among 18 full-sib families of South African grown Eucalyptus grandis: A preliminary investigation. S. Afr. For. J. 146:38-43.

—, AND G. F. R. GERISCHER. 1987. Wood property differences in South African grown Eucalyptus grandis trees of different growth stress intensity. Holzforschung 41: $331-335$.

— J. R. Male, And J. S. M. Venter. 1994. Relationship between the properties of Eucalyptus wood and some chemical, pulp, and paper properties. Paper Southern Africa:6-16.

Miranda, I., AND H. Pereira. 2001. Provenance effect on wood chemical composition and pulp yield for Eucalyptus globulus Labill. Appita J. 54:347-351.

$\longrightarrow$, AND 2 . 2002. Variation of pulpwood quality with provenances and site in Eucalyptus globulus. Ann. For. Sci. 59:283-291.

Mottet, A. 1965. Considerations on the relationship between certain anatomical characteristics and density in tropical woods. Page 15 in Proc. Meeting Section 41 IUFRO, Melbourne.

Muneri, A., And C. A. Raymond. 2001. Nondestructive sampling of Eucalyptus globulus and E. nitens for wood properties. II. Fibre length and coarseness. Wood Sci. Technol. 35:41-56.

Nyakuengama, J. G., R. Evans, C. Matheson, D. Spencer, AND P. Vinden. 1997. Time trends in the genetic control of wood microstructure traits in Pinus radiata. Appita J. 50:486-494.

OHshima, J., S. Yokota, N. Yoshizawa, And T. ONA. 2003. Within-tree variation of detailed fibre morphology and its position representing the whole-tree value in Eucalyptus camaldulensis and E. globulus. Appita J. 56: 476-482. variation of vessel morphology and frequency and representative heights for estimating whole-tree values in $E u$ calyptus camaldulensis and E. globulus. Appita J. 57: 64-69.

ONA, T., AND T. SonODA. 1996. Quality breeding of pulpwood. Cell. Commun. 2 (3):3-7.

, K. ITO, AND M. Shibata. 1995. Studies on decision of selection indexes for quality breeding of eucalypt wood (I). Within-tree variations and the positions representing the whole-tree values of polysaccharides contents on E. camaldulensis and E. globulus. Jpn. Tappi 49:724-734

Y. KoJima. 1996. Use of the radially divided increment core method to assess pulpwood quality for eucalypt breeding in E. camaldulensis and E. globulus. Appita J. 49:325-331.

J. Ohshima, S. Yokota, and N. Yoshizawa. 2001. Investigation of relationships between cell and pulp properties in Eucalyptus by examination of within-tree variations. Wood Sci. Technol. 35:229-243. 
Pot, D., G. Chantre, P. Rozenberg, J. C. Rodrigues, G. L. Jones, H. Pereira, B. Hannrup, C. Cahalan, AND C. Plomion. 2002. Genetic control of pulp and timber properties in maritime pine (Pinus pinaster Ait.). Ann. For. Sci. 59:563-575.

Shelbourne, T., R. Evans, R. P. Kibblewhite, and C. Low. 1997. Inheritance of tracheid transverse dimensions and wood density in radiata pine. Appita J. 50:47-50.

Varghese, M., K. N. Vishnu Subramanian, S. S. R. BenNET, AND S. JaGADEES. 1995. Genetic effects on wood and fibre traits of Eucalyptus grandis Provenances. Proc.
CRCTHF-IUFRO Conference, Eucalypt Plantations: improving fibre yield and quality, Hobart. Pp. 64-67.

Raymond, C. A., P. Bamham, and A. C. MacDonald. 1998. Within tree variation and genetic control of basic density, fibre length and coarseness in Eucalyptus regnans in Tasmania. Appita J. 51:299-305.

WANGAARD, F. F. 1962. Contributions of hardwood fibers to the properties of kraft pulps. Tappi 45:548-556.

Wilson, L., I. Hudson, and K. VAN Beveren. 1997. Vessel distribution at two percentage heights from pith to bark in a 7-year-old E. globulus tree. Appita J. 50:495-500. 